\title{
AlocaÇÃo de Biomassa e NUTRIENTES EM Myriophyllum aquaticum SOB Diferentes NíveIS DE MaCRONUTRIENTES ${ }^{1}$
}

\author{
Allocation of Biomass and Nutrients in Myriophyllum aquaticum at Different Levels of \\ Macronutrient
}

DOMINGOS, V.D. ${ }^{2}$, PASCHOA, P.L. ${ }^{3}$, MARTINS, D. ${ }^{4}$ e COSTA, N.V. ${ }^{2}$

\begin{abstract}
RESUMO - O objetivo deste trabalho foi verificar o efeito de diferentes concentrações de macronutrientes no crescimento e na alocação de biomassa seca em folha, caule e raiz de Myriophyllulm aquaticum. As plantas foram cultivadas em vasos plásticos preenchidos com areia lavada e emersas em solução nutritiva. O experimento foi conduzido em um delineamento inteiramente ao acaso, com quatro níveis $(0,25,50$ e $75 \%)$ da concentração original de N, P, K Ca, Mg e S da solução nutritiva, além de uma testemunha $(100 \%$ da solução nutritiva), com quatro repetições e por um período de 38 dias. A maior produção de biomassa total foi obtida na testemunha. A ausência de $\mathrm{K}$ afetou a alocação de biomassa em raízes. Quanto ao comprimento total dos ramos, a maior resposta ocorreu entre os niveis de Ca a $60 \mathrm{mg} \mathrm{L}^{-1}$. A solução a $100 \%$ dos macronutrientes propiciou o maior comprimento das plantas. $\mathrm{O}$ número de ramos entre os níveis de $\mathrm{N}$ e $\mathrm{P}$ seguiu uma tendência linear $\mathrm{e}$ crescente com as concentrações desses nutrientes, porém em maior proporção para o fósforo. As condições mais favoráveis ao desenvolvimento das plantas ocorreram a $100 \%$ dos macronutrientes da solução base. Entre os níveis de nitrogênio verificaram-se maiores teores de $\mathrm{N}$ nas folhas do que nos caules. Já para os demais nutrientes a alocação desses recursos foi destinada em maior proporção para o caule. A maior alocação de biomassa nesta espécie destinou-se ao caule.
\end{abstract}

Palavras-chave: planta daninha, planta aquática, crescimento.

ABSTRACT - The objective of this work was to verify the effect of different macronutrient concentrations on plant growth and dry biomass allocation in leaves, stems and roots of Myriophyllum aquaticum. The plants were cultivated in plastic pots filled with washed sand and immersed in nutritive solution. The study was carried out in a randomized complete design with four levels of nutrition solution at 0, 25, 50, 75\% from the original concentration solution of $N$, $P, \mathrm{~K} \mathrm{Ca}, \mathrm{Mg}$ and $\mathrm{S}$, besides a control (100\% of the nutritive solution) with 4 replications for 38 days. The largest production of total biomass was obtained in the control plot. The absence of $K$ affected biomass allocation in the roots. The highest total branch length was found among the levels of $\mathrm{Ca}$ at $60 \mathrm{mg} \mathrm{L}^{-1}$. The solution at 100\% of the macronutrients provided the largest plant length. The number of branches among the $N$ and $P$ levels followed a linear and growing tendency with the concentrations of these nutrients, but in a larger proportion for phosphorus. The most favorable conditions to plant development were at 100\% of the macronutrients in the solution base. The highest $N$ levels were verified in the leaves rather than in the stem while for the other nutrients, the greatest allocation was in the stem. Maximum biomass allocation in this species was observed in stems.

Key words: weed, aquatic plant, growth.

Recebido para publicação em 18.1.2005 e na forma revisada em 16.3.2005.

2 Eng.-Agr., M.S., discente de Pós-Graduação, FCA/UNESP, Caixa Postal 237, 18603-970 Botucatu-SP, <vanessadavid@fca.unesp.br>; ${ }^{3}$ Aluno de graduação de Engenharia Agronômica, FCA-UNESP; ${ }^{4}$ Professor Livre Docente, Dep. de Produção Vegetal, FCA/UNESP. 


\section{INTRODUÇÃO}

As plantas aquáticas desempenham importante função na estrutura dos ecossistemas de rios, lagos e represas quando estão em equilíbrio. Quanto às funções ecológicas, encontrase a oferta de alimento e habitat propício para peixes e invertebrados, ciclagem de nutrientes, proteção das margens de corpos hídricos e, ainda, a retenção de nutrientes (Esteves, 1998). Entretanto, quando ocorrem modificações no ambiente, com o despejo de esgotos, o escoamento superficial de solo de áreas agrícolas pode propiciar o aumento da concentração de nutrientes que resultam em sérias perturbações no ecossistema. Dentre os problemas mais freqüentes, incluem-se aqueles relativos a redução na produção de peixes, esportes aquáticos, navegação, irrigação e produção de energia hidrelétrica.

A redução no teor de oxigênio dissolvido na água, decorrente da decomposição de grande quantidade de biomassa produzida pelas plantas aquáticas, pode ser considerada um fator determinante na qualidade da água referente aos seus usos múltiplos.

As plantas aquáticas possuem diferentes graus de colonização, com ampla adaptação em diversas condições ambientais. Esteves (1998) relata que o aumento populacional desordenado destas plantas deve-se a dois fatores principais: à falta de predadores e ao aumento do nivel de eutrofização do ambiente (aumento da oferta de fosfatos e compostos nitrogenados). Guillarmond (1977) ressaltou que Myriophyllum aquaticum desenvolve-se geralmente em ecossistemas altamente afetados pelo homem.

M. aquaticum é uma planta perene, herbácea, que se desenvolve totalmente submersa ou pode apresentar a porção terminal dos ramos sob superficie, variável conforme o nível da água. O enraizamento mantém-se no fundo de lagos com até $2 \mathrm{~m}$ de profundidade ou nas margens, deixando que os ramos avancem pela água (Kissmann, 1997). O ambiente propício ao seu desenvolvimento é: água doce, parada ou com fraca movimentação, com elevado teor de nutrientes, especialmente nitrogênio, e temperaturas entre 8 e $30{ }^{\circ} \mathrm{C}$.

O estudo da biologia de algumas plantas aquáticas emersas, como M. aquaticum, foi realizado por Rejmankova (1992), o qual observou características daninhas nesta espécie, como crescimento rápido, potencial para acúmulo de nitrogênio, maior alocação de biomassa e nitrogênio nas raízes e rápida decomposição. Estas plantas desenvolveramse bem quando submetidas a uma ampla faixa de concentração de $\mathrm{N}$ adicionado em água (20 a $140 \mathrm{mg}$ de $\mathrm{NO}_{3} \mathrm{~L}^{-1}$ ).

As plantas aquáticas possuem estratégias adaptativas que podem ser morfológicas ou fisiológicas, as quais permitem a colonização e o crescimento da densidade populacional em condições ambientais adversas, como a alteração do nível da água em determinada área entre as estações do ano, a exemplo de folhas que podem ficar submersas ou aéreas (Sytsma \& Anderson, 1993).

Sytsma et al. (1993) verificaram em $M$. aquaticum que taxa de crescimento relativo de raízes adventícias apresentou-se maior em relação à planta inteira. Esse comportamento pode sugerir um possível desvio na alocação de biomassa, após a emergência do meristema apical em contato com o ar.

Entre as suas estratégias adaptativas mais conhecidas encontra-se a tolerância à salinidade, a qual inibe o desenvolvimento apenas em concentrações acima de 1\% de cloreto de sódio na água. A reprodução é basicamente vegetativa, com pedaços de ramos de apenas alguns milímetros de comprimento podendo originar uma nova planta (Kissmann, 1997).

As condições ambientais consideradas favoráveis ao crescimento de Myriophilum spicatum, uma outra espécie do mesmo gênero, baseado na maior densidade populacional encontrada, corresponde a $\mathrm{pH}$ da água a 8,74; temperatura da água a $25,1{ }^{\circ} \mathrm{C}$; condutividade elétrica de $0,36 \mathrm{mS} \mathrm{cm}^{-1}$; e concentrações de P-total, N-Total, $\mathrm{Na}, \mathrm{K}^{+}$e $\mathrm{Ca}^{2+}$ equivalentes a $0,92,0,29,21,29,8,79$ e $67,14 \mathrm{mg} \mathrm{L}^{-1}$, respectivamente, em canais de drenagem largos $(28,8 \mathrm{~m})$, com profundidade de 1,47 m (Khedr, 1997).

A alocação de biomassa é um aspecto de competição fundamental, sendo considerada como característica de agressividade de plantas aquáticas. Estas plantas alocam grande parte de sua biomassa para formação de 
cobertura e dependem principalmente de recursos nutricionais estocados para suportar o rápido crescimento de outras espécies competidoras (Sytsma \& Anderson, 1993).

Maine (1998) avaliou a eficiência de algumas plantas aquáticas com relação à remoção de P, destacando-se Salvinia herzogii de la Sota e M. aquaticum. Outros estudos com $M$. aquaticum relacionados à alocação de biomassa, nitrogênio e fósforo demonstraram que os rizomas submersos compreenderam de 72 a $98 \%$ do total de biomassa, enquanto a biomassa emersa não atingiu mais de $24 \%$ do total. Nos rizomas continham somente $3 \%$ do total de $\mathrm{P}$, estando $80 \%$ deste elemento em tecido emerso (Sytsma, 1993).

Assim, o presente trabalho objetivou avaliar o efeito de diferentes concentrações de nutrientes em solução nutritiva na alocação de nutrientes e biomassa de $M$. aquaticum.

\section{MATERIAL E MÉTODOS}

O experimento foi instalado em casa de vegetação no Núcleo de Pesquisas Avançadas em Matologia (NUPAM), pertencente ao Departamento de Produção Vegetal da FCA/ UNESP, campus de Botucatu-SP. As mudas foram obtidas em um canal de drenagem na várzea, localizado na Fazenda Edgardia, pertencente à UNESP, campus de Botucatu.

As mudas foram padronizadas com $20 \mathrm{~cm}$ de comprimento e lavadas com água destilada. As plantas foram cultivadas em vasos plásticos de 4,5 litros (13,8 x 28,3 x 11,8 cm de largura, comprimento e altura, respectivamente), totalizando uma área de superfície aproximada de $0,04 \mathrm{~m}^{2}$, contendo 0,5 litro de areia previamente lavada com água destilada e solução de $\mathrm{HCl}$ a $0,1 \%$. A solução nutritiva constituiuse da diluição da solução de Sarruge (1975) correspondente a $60 \%$ da concentração original.

Nesse substrato foi feito o plantio de uma muda em 0,5 L de solução nutritiva com aeração constante, através de um sistema de mangueiras e registros interligados a compressores de ar.

Para manter as concentrações iniciais de nutrientes durante o intervalo de troca da solução, foram realizadas reposições do volume com água destilada, conforme a evaporação de cada vaso, através do nivel marcado com grafite em uma plaqueta colada na lateral do vaso.

Antes da instalação do experimento definitivo, foi realizado um ensaio preliminar para determinar a concentração de nutrientes da solução de Sarruge (1975) mais próxima dos níveis adequados para a espécie, solução esta utilizada como testemunha no experimento.

Nesse ensaio foram utilizadas cinco diluições, correspondentes a 20, 40, 60, 80 e 100\% da solução de Sarruge (1975), além de uma testemunha constituída por água destilada, as quais foram padronizadas a $\mathrm{pH} 6,5$ por meio da adição de $\mathrm{HCl}$ ou $\mathrm{NaOH}$. O delineamento experimental utilizado neste ensaio foi o inteiramente ao acaso, com seis tratamentos e quatro repetições, por um período de 30 dias. As variáveis analisadas constituíram-se de biomassa seca de folha, caule, raiz e total.

Com base nos resultados obtidos, verificouse que a diluição a $60 \%$ da solução de Sarruge proporcionou maior desenvolvimento da planta para a maioria das variáveis analisadas. Esta solução foi denominada de soluçãobase, à qual foram aplicados individualmente os diferentes niveis de cada nutriente (Tabela 1).

O estudo definitivo foi conduzido durante 38 dias nas mesmas instalações, com procedimentos de montagem e biometria do ensaio anterior. O delineamento experimental utilizado foi o inteiramente ao acaso, com quatro níveis da solução de Sarruge $(0,25,50,75 \%$ da solução-base), avaliados individualmente em N, P, K, Ca, Mg e S, além de uma testemunha (correspondente a $100 \%$ da soluçãobase), com quatro repetições.

A concentração dos nutrientes analisados nas soluções variou entre niveis de 0 a $100 \%$ de $\mathrm{N}\left(0 ; 31,5 ; 63,0 ; 94,5\right.$; e $\left.126,0 \mathrm{mg} \mathrm{L}^{-1}\right), \mathrm{P}(0$; 4,$65 ; 9,3 ; 13,95$; e $\left.18,6 \mathrm{mg} \mathrm{L}^{-1}\right), \mathrm{K}(0 ; 35,1 ; 70,2$; 105,3 ; e $\left.140,4 \mathrm{mg} \mathrm{L}^{-1}\right)$, Ca $(0,30,60,90$ e $\left.120 \mathrm{mg} \mathrm{L}^{-1}\right), \operatorname{Mg}\left(0 ; 7,2 ; 14,4 ; 21,6\right.$; e $\left.28,8 \mathrm{mg} \mathrm{L}^{-1}\right)$ e $\mathrm{S}\left(0 ; 9,6 ; 19,2 ; 28,8 ;\right.$ e $\left.38,4 \mathrm{mg} \mathrm{L}^{-1}\right)$, sendo preservada a concentração dos demais nutrientes com o balanceamento químico necessário. As soluções nutritivas foram renovadas a cada três dias, sendo lavado o substrato com água destilada.

Planta Daninha, Viçosa-MG, v. 23, n. 2, p. 193-201, 2005 
Os parâmetros avaliados constituíram-se de biomassa seca e teor de nutrientes na folha, caule, raiz e total, comprimento total dos propágulos (ramos), índice de ramificação e número de ramos. As plantas foram secas em uma estufa de circulação de ar forçado a 60 ${ }^{\circ} \mathrm{C}$. O índice de ramificação foi obtido a partir da relação do comprimento de ramos secundários e terciários sobre o comprimento total de ramos na planta. O acúmulo de nutrientes nos órgãos da planta representa o teor do nutriente na biomassa seca produzida.

A determinação dos nutrientes $(\mathrm{N}, \mathrm{P}, \mathrm{K}$, $\mathrm{Ca}, \mathrm{Mg}$ e S) nas diferentes partes da planta foi realizada no Laboratório de Relação Solo/ Planta do Departamento de Produção Vegetal, da FCA-Unesp/Botucatu. Para determinação dos teores de $\mathrm{N}$, o material vegetal foi submetido à digestão sulfúrica; para os demais macronutrientes utilizou-se uma mistura de ácido nitro-perclórico, seguindo metodologia proposta por Malavolta et al. (1989). A determinação de $\mathrm{N}$ foi feita por titulometria, e a dos outros macronutrientes, por espectrometria de plasma.

Os resultados obtidos foram submetidos à análise de variância pelo teste $\mathrm{F}$, e a comparação de médias foi feita pelo teste t a $5 \%$ de probabilidade. As análises de regressão foram realizadas com as médias, utilizando-se o programa Jandel Sigma Stat 2.0, sendo apresentadas apenas as regressões que foram significativas.

\section{RESULTADOS E DISCUSSÃO}

A biomassa seca total de $M$. aquaticum, em função dos diferentes niveis de nutrientes aplicados, apresentou resposta mais evidente na solução mais concentrada, independentemente do nutriente (Tabela 1). A produção máxima obtida com a solução de $100 \%$ de macronutrientes foi de $8,3 \mathrm{~g} \mathrm{em} 0,04 \mathrm{~m}^{-2}$, que pode ser equivalente a $207,8 \mathrm{~g} \mathrm{~m}^{-2}$ ou a $2.080 \mathrm{~kg} \mathrm{ha}^{-1}$ de biomassa total produzida em 38 dias. Madsen (1997) avaliou a dinâmica sazonal da biomassa de $M$. spicatum, uma outra espécie do mesmo gênero, em tanques experimentais e encontrou valores entre 700 e $1.200 \mathrm{~g} \mathrm{~m}^{2}$. Já na ausência de $\mathrm{N}$ e $\mathrm{P}, M$. aquaticum produziu respectivamente para estes nutrientes 2,44 e 3,35 g 0,04 $\mathrm{m}^{-2}$, correspondente a 610,4 e $839,4 \mathrm{~kg} \mathrm{ha}^{-1}$ em relação ao mesmo período avaliado.

Com base nesses resultados, verifica-se que esta espécie possui elevado potencial de colonização referente à quantidade de biomassa acumulada em aproximadamente 40 dias, mesmo na ausência de $\mathrm{N}$ e P. Shibayama (1990), citado por Sytsma \& Anderson (1993), relatou que em ambiente natural no Japão a produção de biomassa fresca de $M$. aquaticum encontrada foi de $13,3 \mathrm{~kg} \mathrm{~m}^{-2}$. Enquanto Monteiro e Moreira (1990) encontraram valores entre 22 e $26 \mathrm{~kg} \mathrm{~m}^{-2}$. Esses resultados, quando comparados com os obtidos, embora avaliados em termos de biomassa fresca, permitem obter uma análise mais realista das inferências citadas sobre a produção de biomassa que foram avaliadas em condições ótimas de crescimento, sem a interferência de outros fatores como clima e competição entre espécies.

As maiores produções de biomassa total foram obtidas entre 100 e $126 \mathrm{mg} \mathrm{L}^{-1}$ de $\mathrm{N} ; 15$ a $18,6 \mathrm{mg} \mathrm{L}^{-1}$ de P; e 10 a $30 \mathrm{mg} \mathrm{L}^{-1}$ de $\mathrm{Mg}$. Observa-se em relação ao $\mathrm{Mg}$ uma menor amplitude dos resultados para a produção de biomassa em comparação ao $\mathrm{N}, \mathrm{K}$ e P. Isso pode indicar que esta espécie apresenta maior exigência na absorção de $\mathrm{N}, \mathrm{K}$ e $\mathrm{P}$, uma vez que a demanda por estes nutrientes está relacionada com a sua função vital no metabolismo da planta como constituinte de moléculas estruturais e equilibrio osmótico, bem como fonte de energia para o desenvolvimento da planta (Marschner, 1995).

A redução observada no nível de $75 \%$ para $\mathrm{K}$ e S, provavelmente, pode ser decorrente de um desbalanço nutricional ocasionado pelo

Tabela 1 - Biomassa total de Myriophyllum aquaticum sob o efeito de diferentes níveis de macronutrientes

\begin{tabular}{|c|c|c|c|c|c|c|}
\hline $\begin{array}{c}\text { Solução } \\
(\%)\end{array}$ & $\mathrm{N}$ & $\mathrm{P}$ & $\mathrm{K}$ & $\mathrm{Ca}$ & $\mathrm{Mg}$ & $\mathrm{S}$ \\
\hline 0 & $2,44 \mathrm{c}$ & $3,36 \mathrm{~d}$ & $3,00 \mathrm{~d}$ & $4,86 \mathrm{~b}$ & $4,17 \mathrm{~b}$ & $4,30 \mathrm{c}$ \\
\hdashline 25 & $4,71 \mathrm{bc}$ & $4,56 \mathrm{~cd}$ & $5,82 \mathrm{bc}$ & $6,15 \mathrm{ab}$ & $8,13 \mathrm{a}$ & $7,07 \mathrm{ab}$ \\
\hdashline 50 & $6,17 \mathrm{ab}$ & $6,9 \mathrm{bc}$ & $7,60 \mathrm{ab}$ & $8,14 \mathrm{a}$ & $8,00 \mathrm{a}$ & $8,10 \mathrm{a}$ \\
\hdashline 75 & $6,52 \mathrm{ab}$ & $5,47 \mathrm{ab}$ & $5,59 \mathrm{c}$ & $6,92 \mathrm{ab}$ & $8,12 \mathrm{a}$ & $5,11 \mathrm{bc}$ \\
\hdashline 100 & $8,32 \mathrm{a}$ & $8,32 \mathrm{a}$ & $8,32 \mathrm{a}$ & $8,32 \mathrm{a}$ & $8,32 \mathrm{a}$ & $8,32 \mathrm{a}$ \\
\hline $\mathrm{F}$ & $4,86^{* *}$ & $8,9 * *$ & $10,92^{* *}$ & $4,07^{*}$ & $5,19^{* *}$ & $4,08^{*}$ \\
\hline $\mathrm{CV}(\%)$ & 35,4 & 22,86 & 20,63 & 21,64 & 21,24 & 27,09 \\
\hdashline $\mathrm{DMS}$ & 3,00 & 1,98 & 1,88 & 2,19 & 2,35 & 2,68 \\
\hline
\end{tabular}


efeito de inibição competitiva entre outros cátions divalentes, que pode ter influenciado a produção de biomassa total. Quanto ao Ca e $\mathrm{S}$, verificou-se que a ausência destes nutrientes afetou significativamente a produção de biomassa total.

A distribuição de biomassa expressa em porcentagem e peso entre os componentes da planta foi alterada em função dos niveis de nutrientes aplicados (Figura 1). A biomassa de folhas, caules e raízes obtida na solução mais concentrada dos nutrientes foi de 2,97, 4,22 e $1,13 \mathrm{~g}$ por planta, respectivamente. Observouse que houve menores incrementos na biomassa de folha em relação ao caule, o que
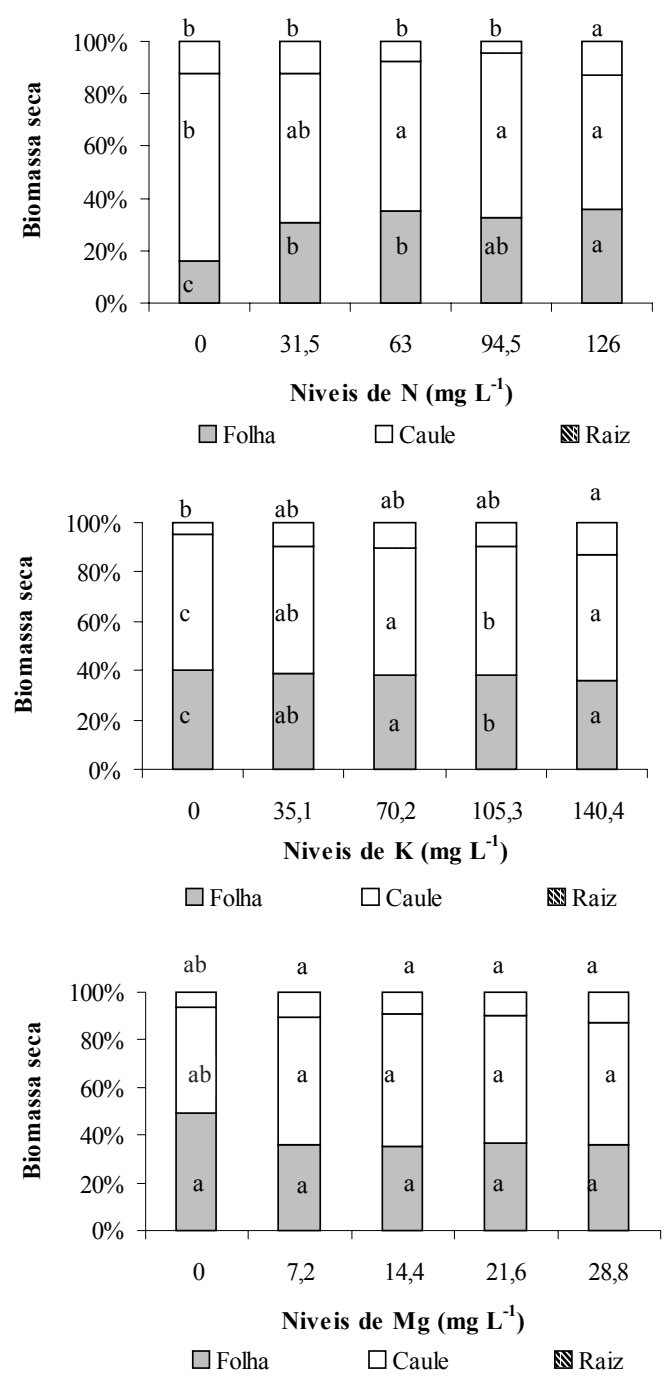

indica um desvio de alocação de parte dos fotoassimilados em maior proporção neste órgão. Enquanto, entre os níveis de 94,5 e $126,0 \mathrm{mg} \mathrm{L}^{-1}$ de $\mathrm{N}$, os incrementos em folhas e raizes (referente ao nivel mais concentrado) foram significativos.

A distribuição percentual da biomassa seca das diferentes partes da planta de $M$. aquaticum, sob diferentes niveis de macronutrientes, é apresentada na Tabela 2 . Observa-se que os acúmulos de biomassa no caule e na folha entre os níveis de $\mathrm{N}$ foram, em média de 60,4 e $29,5 \%$, respectivamente; na ausência de $\mathrm{N}$, os valores encontrados foram de 71,7 e $15,9 \%$, para caule e folha,
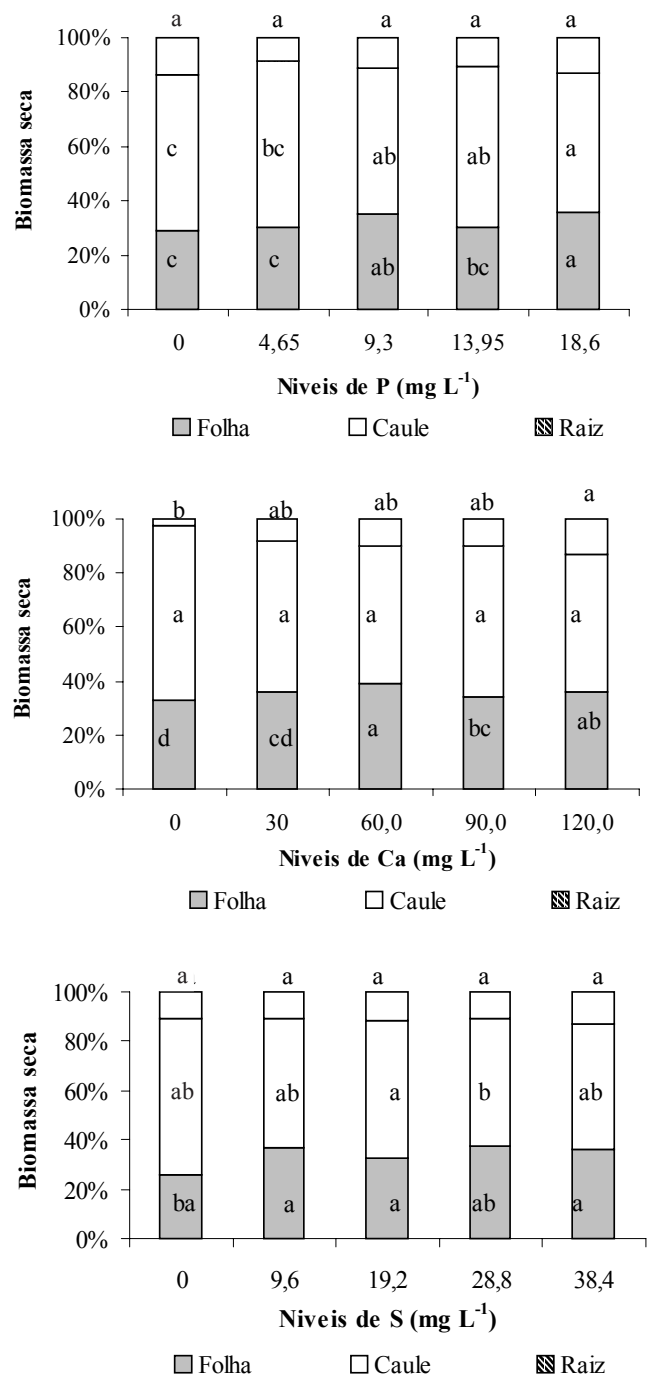

Figura 1 - Distribuição da biomassa entre os componentes vegetativos de Myriophyllum aquaticum sob o efeito de diferentes níveis de macronutrientes. Botucatu-SP, 2004. 
respectivamente. Essas alterações nos padrões de alocação de biomassa possibilitam inferir que, em ambientes com menores concentrações de nitrogênio, $M$. aquaticum prioriza a biomassa de caule, uma vez que este órgão é responsável pela propagação da espécie.

Quanto aos níveis de P, para biomassa de folha houve uma resposta crescente com o aumento da concentração do nutriente; os acúmulos entre os niveis foram em média, no caule, de $56,4 \%$, na folha, de $32 \%$, e na raiz, de $11,6 \%$. Verificou-se que a ausência de P não afetou a proporção de raízes, pois entre os níveis de 0 e $100 \%$ a proporção de raízes foi semelhante, correspondente a 13,09 e 13,54\% do total.

Sytsma \& Anderson (1993) destacaram que a proporção de raízes de $M$. aquaticum em ambientes naturais geralmente não é maior do que $12 \%$ da biomassa total. Esses resultados ressaltaram o potencial da planta em relação à sobrevivência em ambientes com diversas concentrações de fósforo.

Tabela 2 - Distribuição percentual da biomassa seca das diferentes partes da planta de Myriophyllum aquaticum sob diferentes níveis de macronutrientes

\begin{tabular}{|c|c|c|c|c|c|}
\hline \multirow{2}{*}{$\begin{array}{c}\text { Estrutura } \\
(\%)\end{array}$} & \multicolumn{5}{|c|}{ Níveis de N (\%) } \\
\cline { 2 - 6 } & $0^{1 /}$ & 25 & 50 & 75 & 100 \\
\hline Folha & 15,91 & 30,81 & 31,76 & 33,14 & 35,69 \\
\hline Caule & 71,69 & 56,71 & 60,39 & 62,48 & 50,78 \\
\hline Raiz & 12,40 & 12,47 & 7,85 & 4,38 & 13,54 \\
\hline \multicolumn{7}{|c|}{ Níveis de P (\%) } \\
\hline Folha & 28,89 & 29,84 & 34,74 & 30,69 & 35,69 \\
\hline Caule & 58,02 & 61,36 & 53,03 & 58,89 & 50,78 \\
\hline Raiz & 13,09 & 8,80 & 12,23 & 10,42 & 13,54 \\
\hline \multicolumn{7}{|c|}{ Níveis de K (\%) } \\
\hline Folha & 39,75 & 38,91 & 38,38 & 37,31 & 35,69 \\
\hline Caule & 55,23 & 51,62 & 51,71 & 52,42 & 50,78 \\
\hline Raiz & 5,02 & 9,47 & 9,92 & 10,27 & 13,54 \\
\hline \multicolumn{7}{|c|}{ Níveis de Ca (\%) } \\
\hline Folha & 32,90 & 35,66 & 38,69 & 30,36 & 35,69 \\
\hline Caule & 64,49 & 56,21 & 51,59 & 59,95 & 50,78 \\
\hline Raiz & 2,60 & 8,13 & 9,72 & 9,69 & 13,54 \\
\hline \multicolumn{7}{|c|}{ Níveis de Mg (\%) } \\
\hline Folha & 48,44 & 35,98 & 35,13 & 36,03 & 35,69 \\
\hline Caule & 45,01 & 52,96 & 55,51 & 54,23 & 50,78 \\
\hline Raiz & 6,55 & 11,06 & 9,36 & 9,73 & 13,54 \\
\hline \multicolumn{7}{|c|}{ Niveis de S (\%) } \\
\hline Folha & 25,81 & 36,47 & 32,60 & 37,09 & 35,69 \\
\hline Caule & 62,86 & 52,45 & 55,46 & 51,71 & 50,78 \\
\hline Raiz & 11,33 & 11,08 & 11,94 & 11,20 & 13,54 \\
\hline
\end{tabular}

${ }^{1 /} 0,25,50,75$ e 100 correspondem às porcentagens do nutriente na solução-base.
A proporção de folha, caule e raiz entre os níveis de $\mathrm{K}$ foi, em média, de 38,0, 52,4 e 9,6\%, respectivamente. A ausência de $\mathrm{K}$ afetou a alocação de biomassa em raízes, quando se compara aos niveis mais concentrados. Marschner (1995) relata que, exceto o nitrogênio, o potássio é considerado o nutriente requerido em maior quantidade pelas plantas e desempenha várias funções em processos metabólicos - como transporte no floema, extensão celular, compartimentação e concentração celular, balanço cátion-ânion e sintese de proteina - que estão relacionados à produção de raízes. Em condições de deficiência, pode causar alterações na redistribuição do K, o qual pode ser transportado para folhas e caules. Portanto, a redução de biomassa de raízes no nível 0 , talvez, seja devido a uma redistribuição do $\mathrm{K}$ da raiz para folha e caule.

A alocação de biomassa em raízes na ausência de Ca apresentou redução significativa, referente a 2,6\% do total de biomassa. Esse fato destaca a importância do Ca para o desenvolvimento de raízes, sendo de conhecimento comum a participação deste nutriente na constituição da parede celular.

Para os níveis de $\mathrm{Mg}$, os acúmulos de biomassa em folhas, caules e raízes, apresentaram reduções em relação aos outros níveis. Já no caule houve uma tendência de maiores produções de biomassa entre os niveis de 25 e $75 \%$ (7,2 e 21,6 $\left.\mathrm{mg} \mathrm{L}^{-1} \mathrm{de} \mathrm{Mg}\right)$.

Verificou-se que, entre os níveis de 0 e $75 \%$ de S, a biomassa acumulada nas raízes não apresentou diferenças. Todavia, as folhas apresentaram redução significativa.

O padrão de alocação de biomassa nas diferentes partes da planta representa uma estratégia comum em plantas aquáticas, aumentando a competição entre espécies em ambientes estressados (Sytsma \& Anderson, 1993). M. aquaticum pode ser considerada uma espécie agressiva na invasão de grandes áreas de ecossistemas aquáticos que apresentam niveis de $\mathrm{P}, \mathrm{N}$ e $\mathrm{Mg}$ favoráveis ao seu desenvolvimento. A alocação de biomassa nesta espécie destina grande parte dos recursos nutricionais para o caule, que representa o principal meio de propagação.

Na Figura 2 estão apresentados os resultados de comprimento total, índice de 
ramificação e número de ramos de $M$. aquaticum em função de diferentes nivieis de $\mathrm{N}$ e $\mathrm{P}$, os quais apresentaram modelos de regressão significativos.

Quanto ao comprimento total dos ramos, observou-se resposta linear e crescente com os niveis de $\mathrm{N}$ e $\mathrm{P}$; o maior comprimento
$(440,25 \mathrm{~cm})$ foi observado a $126 \mathrm{mg} \mathrm{L}^{-1} \mathrm{de} \mathrm{N}$, e a maior exigência pode ser verificada para $\mathrm{o}$ nitrogênio, que na ausência condicionou maior redução neste parâmetro. Já entre os níveis de $\mathrm{P}$ os resultados variaram de 104,0 a $340,0 \mathrm{~cm}$. Entre os niveis de $\mathrm{K}$ e Ca o ajuste da regressão não foi significativo, porém a maior resposta foi obtida a 70,2 e 60,0 $\mathrm{mg} \mathrm{L}^{-1}$,
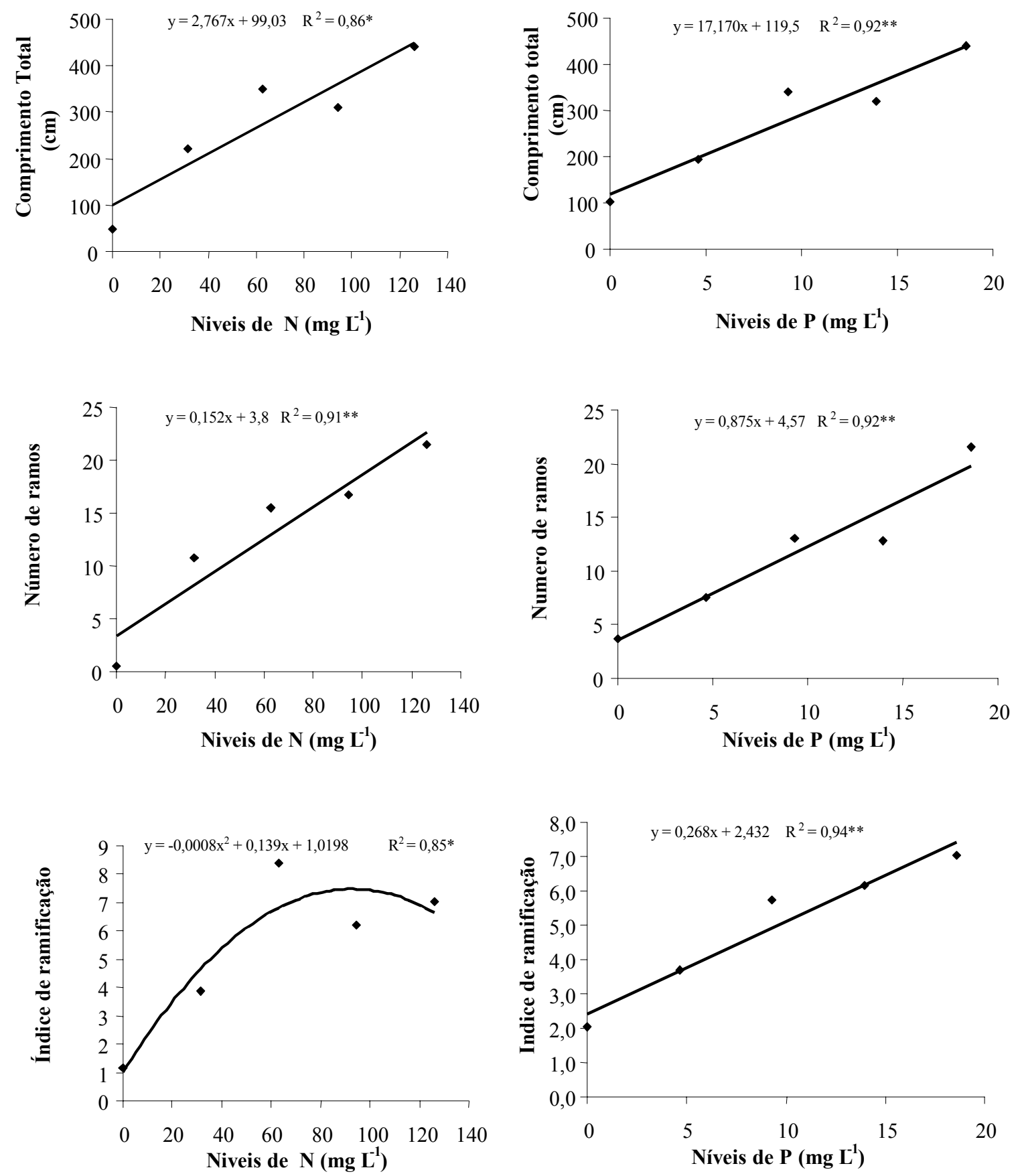

Figura 2 - Efeito de diferentes níveis de nitrogênio e fósforo no desenvolvimento de Myriophyllum aquaticum. Botucatu-SP, 2004. 
referentes a 465,13 e 557,0 cm. Quanto a $\mathrm{Mg}$ e S, $M$. aquaticum foi mais responsivo nos menores niveis, mas em maior proporção entre as concentrações de enxofre.

$\mathrm{O}$ número de ramos entre os niveis de $\mathrm{N}$ (2 a 23 ramos por planta) e $\mathrm{P}$ ( 5 a 23 ramos por planta) também apresentou uma tendência linear e crescente com as concentrações destes nutrientes, porém em maior intensidade para o fósforo, como pode ser verificado na equação de regressão, a qual demonstra um coeficiente linear de 0,876 e, para o nitrogênio, de 0,152 , que são correspondentes ao aumento no número de ramos para cada $1 \mathrm{mg} \mathrm{L}^{-1}$ de $\mathrm{P}$ ou $\mathrm{N}$ adicionados ao ambiente de crescimento.

Quanto ao índice de ramificação, verificaram-se comportamentos diferentes entre $\mathrm{N}$ e $\mathrm{P}$, os quais se ajustaram aos modelos quadrático e linear. Portanto, o aumento na concentração de fósforo pode induzir ao crescimento de uma planta mais ramificada, o que aumenta o potencial de infestação. O nitrogênio apresenta uma tendência de maior ramificação até $60 \mathrm{mg} \mathrm{L}^{-1}$, a partir desta concentração, o crescimento ocorre em comprimento, constatado na tendência linear apresentada no comprimento total da planta.

O acúmulo de nutrientes na biomassa seca total sob o efeito de diferentes concentrações de macronutrientes apresentou tendência linear e crescente com o aumento da concentração dos respectivos elementos, com exceção do potássio (Figura 3). Verificou-se que o teor de $\mathrm{P}$ na biomassa produzida pela planta apresentou respostas mais evidentes em relação aos demais nutrientes, o que pode ser verificado pelo coeficiente linear correspondente a 1,9 para cada $1 \mathrm{mg} \mathrm{L}^{-1}$ de $\mathrm{P}$ adicionado à solução de crescimento.

A alocação dos acúmulos de nutrientes nos diferentes órgãos da planta apresentou significância ao modelo linear apenas para folha e caule, com exceção dos níveis de potássio e enxofre (Figura 4). Verificou-se, entre os niveis de nitrogênio, que os teores de $\mathrm{N}$ foram maiores nas folhas o que nos caules, os quais apresentaram acúmulo de 133,97 e 70,72 mg por planta.
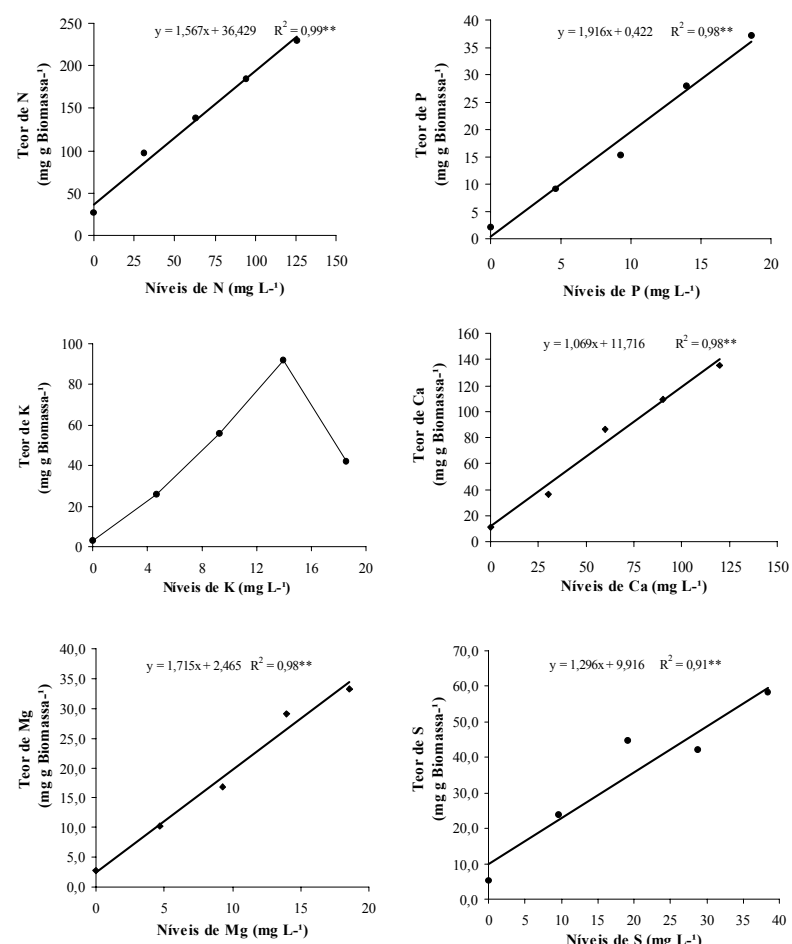

Figura 3 - Acúmulo de nutrientes na biomassa total de Myriophyllum aquaticum sob o efeito de diferentes níveis de macronutrientes. Botucatu-SP, 2004.
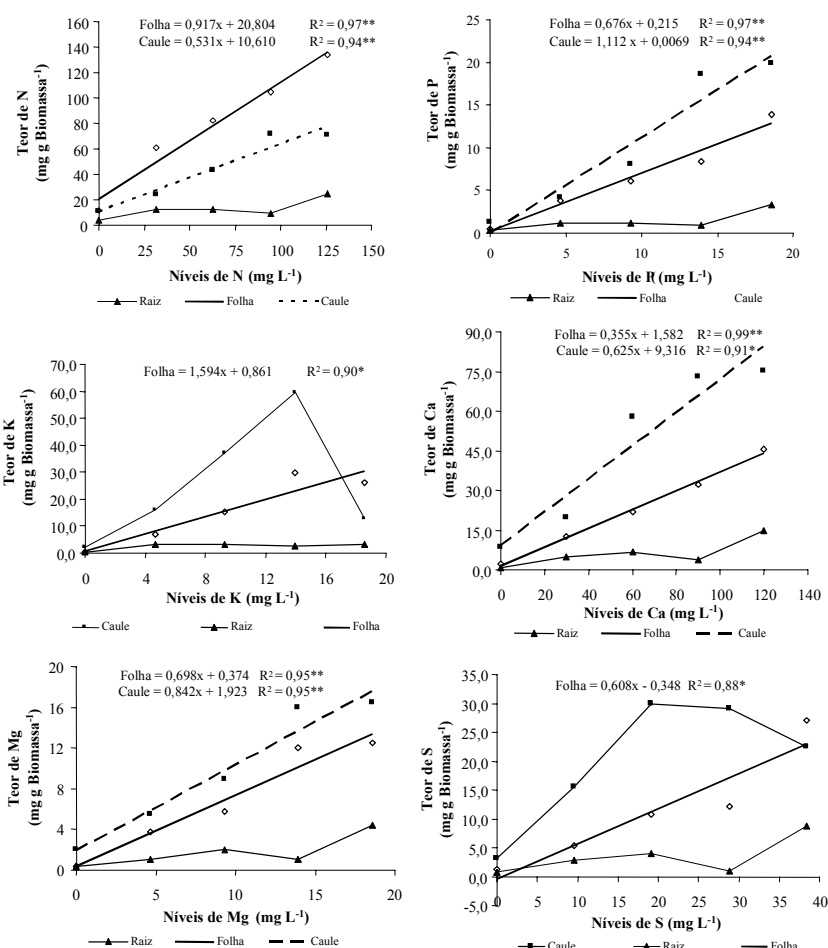

Figura 4 - Acúmulo de nutrientes na biomassa de diferentes partes da planta de Myriophyllum aquaticum sob o efeito de diferentes níveis de macronutrientes. Botucatu-SP, 2004. 
Para os demais nutrientes, a alocação desses recursos foi destinada em maior proporção no caule. Quanto ao P, esse comportamento fica mais evidente em concentrações maiores que $5 \mathrm{mg} \mathrm{L}^{-1}$, sendo no nível mais concentrado constatados os maiores teores no caule e na folha, correspondentes a 19,89 e $13,88 \mathrm{mg}$ por planta, respectivamente.

Os teores de $\mathrm{K}, \mathrm{Ca}$ e $\mathrm{Mg}$ no caule foram crescentes com o nível de sua concentração sempre em maior proporção do que na folha. $\mathrm{Em}$ relação ao $\mathrm{S}$, observaram-se acúmulos crescentes no caule até $19,2 \mathrm{mg} \mathrm{L}^{-1}$ de $\mathrm{S}$, com redução em concentrações maiores que $30 \mathrm{mg} \mathrm{L}^{-1}$ de $\mathrm{S}$; na folha, houve tendência linear com o nível de enxofre na solução. Isso pode indicar uma possivel alteração na alocação deste nutriente, referente à translocação do caule para a folha, quando a planta está condicionada em ambientes com maiores concentrações, o que provavelmente, se deve à alta mobilidade do elemento na planta.

A alocação de biomassa e nutrientes em $M$. aquaticum destina grande parte dos recursos nutricionais e fotoassimilados para o caule, o qual representa o principal meio de propagação da espécie.

\section{LITERATURA CITADA}

AMOROS, C.; BORNETE, G.; HENRY, C. P. A vegetation based method ecological diagnosis of riverine wetlands.

Environ. Manag., v. 25, n. 2, p. 211-227, 2000.

BAATTRUP-PEDERSEN, A.; LARSEN, S. E.; RISS, T. Composition and richness of macrophyte communities in small Danish streams - influence of environmental factors and weed cutting. Hidrobiologia, v. 495, p. 171-179, 2003.

ESTEVES, F. A. Fundamentos de limnologia. 2.ed. Rio de Janeiro: Interciência, 1998. 602 p.
GUILLARMOND, A. J. Myriophyllum, na increasing water weed menace for South Africa. South Afr. J. Sci., v. 73, p. 89-90, 1977.

KHEDR, A. H. A. et. al. Distribution of aquatic plants in relation to environmental factors in the Nile Delta. Aquat. Bot., v. 56, p. 75-86, 1997.

KISSMANN, K. G. Plantas infestantes e nocivas. 2.ed. São Paulo: Basf Brasileira, 1997. 825 p.

MADSEN, J. D. Seasonal biomass and carbohydrate allocation in a southern population of Eurasian Watermilfoil. J. Aquat. Plant. Manag., v. 35, p. 15-21, 1997.

MAINE, M. A. Role of macrophytes in phosphoros removal in Paraná medio wetlands. Polskie-Archiwum. Hidrobiologia, v. 45, p. 23-34, 1998.

MALAVOLTA, E. et al. Avaliação do estado nutricional de plantas: princípios e aplicações. 2.ed. Piracicaba: Potafós, 1989. 319 p.

MARSCHNER, H. Mineral nutrition of higher plants. 2.ed. San Diego: Academic Press, 1995. 674 p.

MONTEIRO, A.; MOREIRA, I. Chemical control of parrotfeather (Myriophyllum aquaticum). EWRS Symposium on Aquatic Weeds, v. 8, p. 163-164, 1990.

REJMANKOVA, E. Ecology of creeping macrophytes whith special reference to Ludwigia peploides (H.B.K.) Raven. Aquat. Bot., v. 43, p. 283-299, 1992.

SARRUGE, J.R. et. al. Soluções nutritivas. Summa Phytopathol., v. 1, n. 3, p. 231-233, 1975.

SYTSMA, M. D et. al. Criteria for assessing nitrogen and. Phosphorus deficiency in Myriophyllum aquaticum. J. Freshwater Ecol., v. 8, p. 115-164, 1993.

SYTSMA, M. D.; ANDERSON, L. W. J. Biomass, nitrogen, and phosphorus allocation in parrotfeather (Myriophyllum aquaticum). J. Aquat. Plant Manag., v. 31, p. 244-248, 1993. 